\title{
Dilute-Solution Properties of Polystyrene Polymacromonomer Having Side Chains of over 100 Monomeric Units
}

\author{
By Manabu SUGIYAMA, ${ }^{1}$ Yo NAKAMURA, ${ }^{2, *}$ and Takashi NORISUYE ${ }^{1}$
}

\begin{abstract}
Static and dynamic light scattering and viscosity measurements were made on 12 samples of polymacromonomer F110 consisting of polystyrene with 113 styrene units in each side chain to determine the z-average mean-square radius of gyration, the hydrodynamic radius, and the intrinsic viscosity in cyclohexane at $34.5^{\circ} \mathrm{C}$ (the theta temperature) and toluene at $15.0^{\circ} \mathrm{C}$ as functions of weight-average molecular weight $M_{\mathrm{w}}$. Small-angle X-ray scattering experiment was also performed for one sample in the two solvents. The dependence of the three measured properties on $M_{\mathrm{w}}$ in the range $1.9 \times 10^{5}-1.3 \times 10^{7}$ studied were consistently explained by available theories for the wormlike chain with $M_{\mathrm{L}}$ (the molar mass per unit contour length) $=45500 \mathrm{~nm}^{-1}, \lambda^{-1}$ (the stiffness parameter) $=80 \mathrm{~nm}$ (in cyclohexane) or $155 \mathrm{~nm}$ (in toluene), and $d$ (the chain diameter) $=16-26 \mathrm{~nm}$ (depending on the kind of solvent and measured property) when the end effect arising from side chains near the main-chain ends was taken into account. The side-chain length dependence of $\lambda^{-1}$, examined with the aid of previous data for three polystyrene polymacromonomers with shorter side chains of 15,33 , and 65 styrene units, was found to be almost quantitatively explained by the theory of Nakamura and Norisuye [Polym. J., 33, 874 (2001)]. That of $d$ was also discussed in relation to the end-to-end distance of a wormlike side chain.

KEY WORDS: Polymacromonomer / Radius of Gyration / Hydrodynamic Radius / Intrinsic Viscosity / Chain Stiffness / Chain

Thickness /
\end{abstract}

We have studied polymacromonomers consisting of polystyrene (PS) having side chains of 15,33 , and 65 monomeric units (F15, F33, and F65, respectively) in cyclohexane (a theta solvent) and toluene (a good solvent) by static $^{1-3}$ and dynamic $^{4,5}$ light scattering, small-angle X-ray scattering (SAXS), ${ }^{6,7}$ and viscosity measurements. ${ }^{3,8}$ The z-average mean-square radius of gyration $\left\langle S^{2}\right\rangle_{\mathrm{z}}$, the hydrodynamic radius $R_{\mathrm{H}}$, and the intrinsic viscosity $[\eta]$ obtained as functions of weight-average molecular weight $M_{\mathrm{w}}$ were explained in a consistent manner by the Kratky-Porod (KP) wormlike chain model, ${ }^{9}$ and the estimated backbone stiffness parameter (or Kuhn segment length) $\lambda^{-1}$ and chain diameter $d$ were found to depend on the side chain length and the solvent quality, being consistent with observations on different polymacromonomers by other groups. ${ }^{10-14}$ To establish the relations between these molecular parameters and the side chain length, however, further work was highly desirable for polymacromonomers with longer side chains.

The present paper reports an experimental study thus undertaken as an extension of our previous light scattering, SAXS, and viscosity studies to a series of PS polymacromonomer samples (designated F110) with 113 side chain units. The data obtained from these methods are comprehensively analyzed, and the side chain length dependence of $\lambda^{-1}$ and $d$ is discussed. With regard to the sample preparation, which was actually crucial to the present study, a brief remark may be in order.

For very thick chains, samples with large polymerization degrees $N$ of main chain are needed for an unequivocal determination of $\lambda^{-1}$, but the preparation of such is generally difficult. To circumvent the difficulty, we synthesized a very large quantity of PS macromonomer composed of about 110 styrene units in essentially the same way as that described previously. ${ }^{1,3}$ We then divided it into many parts and polymerized them one by one to find the most suitable condition. PS polymacromonomer samples thus obtained were found to contain components with $N$ larger than 1000, and were carefully fractionated to obtain a series of samples covering a broad range of $N$.

\section{EXPERIMENTAL}

\section{Preparation of Polymacromonomer Samples}

Styrene (about $150 \mathrm{~mL}$ ) was polymerized with benzyl lithium as an anionic initiator in $1 \mathrm{~L}$ of toluene and terminated by excess 4-vinylbenzylchloride (VBC). The macromonomer thus obtained was reprecipitated four times to remove unreacted VBC. Its $M_{\mathrm{w}}$ and the weight to number-average molecular weight ratio $M_{\mathrm{w}} / M_{\mathrm{n}}$ were determined by light scattering in cyclohexane at $34.5^{\circ} \mathrm{C}$ and size exclusion chromatography (SEC), respectively, to be $M_{\mathrm{w}}=11900$ and $M_{\mathrm{w}} / M_{\mathrm{n}}=1.05$.

The PS macromonomer (about $10 \mathrm{~g}$ in each preparation) was polymerized with azobisisobutyronitrile as an initiator at various temperatures $42-60^{\circ} \mathrm{C}$ and macromonomer concentrations $54-86 \%(\mathrm{w} / \mathrm{w})$ in benzene. The highest molecular weight was reached under the following conditions: monomer concentration, $81 \%(\mathrm{w} / \mathrm{w})$; initiator concentration, $0.024 \mathrm{~mol} /$

\footnotetext{
${ }^{1}$ Department of Macromolecular Science, Osaka University, 1-1 Machikaneyama-cho, Toyonaka 560-0043, Japan

${ }^{2}$ Department of Polymer Chemistry, Kyoto University, Katsura, Kyoto 615-8510, Japan

*To whom correspondence should be addressed (Tel: +81-75-383-2625, Fax: +81-75-383-2628, E-mail: yonaka@molsci.polym.kyoto-u.ac.jp).
} 
$\mathrm{L}$; polymerization time, $164 \mathrm{~h}$; temperature, $45^{\circ} \mathrm{C}$. Under these conditions, the yield was as high as $77 \%$ and the apparent molecular weight estimated from the peak position of SEC with the calibration curve for linear polystyrene was $2.84 \times 10^{6}$.

The polymacromonomer samples thus obtained were fractionated by repeated fractional precipitation in toluene-methanol mixtures for low molecular weight samples and in cyclohexane for high molecular weight samples. Twelve fractions (designated below as F110-1, F110-2, ..., F110-12 from high to low molecular weight) were chosen for the present study. The values of $M_{\mathrm{w}} / M_{\mathrm{n}}$ for F110-4-F110-9 were in the range 1.09-1.14 when determined from SEC with the calibration curve constructed for this polymacromonomer.

\section{Static Light Scattering}

Five solutions with different concentrations were prepared for each sample in the respective solvents. They were made optically clean by use of a membrane filter of $0.45 \mu$ pore size. Measurements were made at 15.0 and $34.5^{\circ} \mathrm{C}$ (controlled within $\pm 0.05^{\circ} \mathrm{C}$ ) for toluene and cyclohexane solutions, respectively, on a Fica-50 light scattering photometer with vertically polarized incident light of 436 or 546-nm wavelength in the manner employed in our previous studies; for samples F110-9 and F110-11 in cyclohexane, data were also taken at other temperatures $T$ of $25,30,40$, and $45^{\circ} \mathrm{C}$.

Excess reduced scattering intensities $R_{\theta}$ obtained at scattering angles $\theta$ between 30 and $150^{\circ}$ were analyzed by means of the square-root plot, ${ }^{15}$ i.e., $\left(K c / R_{\theta}\right)^{1 / 2}$ against $\sin ^{2}(\theta / 2)$ or against $c$ (the solute mass concentration) to obtain $M_{\mathrm{w}},\left\langle S^{2}\right\rangle_{\mathrm{z}}$, and $A_{2}$ (the second virial coefficient), where $K$ denotes the optical constant. The mass concentration was calculated from the gravimetrically determined weight fraction with the solution density $\rho$. The density increment $(\partial \rho / \partial c)$ was determined by an Anton-Paar DMA5000 densitometer to be 0.200 in toluene at $15^{\circ} \mathrm{C}$ and 0.289 in cyclohexane at $34.5^{\circ} \mathrm{C}$. Its values for cyclohexane solutions were found to change with the temperature coefficient $\mathrm{d}(\partial \rho / \partial c) / \mathrm{d} T=5.6 \times 10^{-4} \mathrm{~K}^{-1}$ for $25^{\circ} \mathrm{C} \leq T \leq 45^{\circ} \mathrm{C}$.

Specific refractive index increments $\partial n / \partial c$ in cyclohexane at $25,30,34.5,40$, and $45^{\circ} \mathrm{C}$ and in toluene at $15^{\circ} \mathrm{C}$ were measured by using a modified Schulz-Cantow type differential refractometer. The results for toluene solutions were 0.107 and $0.103 \mathrm{~cm}^{3} \mathrm{~g}^{-1}$ for 436 and $546 \mathrm{~nm}$, respectively, and those for cyclohexane solutions at $34.5^{\circ} \mathrm{C}$ were 0.179 and $0.172 \mathrm{~cm}^{3} \mathrm{~g}^{-1}$ for 436 and $546 \mathrm{~nm}$, respectively, with the temperature coefficient $\mathrm{d}(\partial n / \partial c) / \mathrm{d} T$ of $6.0 \times 10^{-4}\left(\mathrm{~cm}^{3} \mathrm{~g}^{-1} \mathrm{~K}^{-1}\right)$ for both wavelengths in the $T$ range between 25 and $45^{\circ} \mathrm{C}$.

\section{Small-Angle X-ray Scattering}

SAXS measurements were made on sample F110-9 in cyclohexane $\left(34.5^{\circ} \mathrm{C}\right)$ and toluene $\left(25.0^{\circ} \mathrm{C}\right)$ at a beam line BL40B2 in a synchrotron facility SPring8 (Proposal No 2007A1556) to estimate the chain diameter in each solvent. The camera length and the wavelength of the incident X-ray were set to $1.5 \mathrm{~m}$ and $0.1 \mathrm{~nm}$, respectively. A test solution in a quartz glass capillary of $1.5 \mathrm{~mm}$ in diameter was kept within $\pm 0.1^{\circ} \mathrm{C}$ by circulation of temperature-regulated water through a capillary holder. Four different concentrations were studied for the respective solvents, with intensity data accumulated for $5 \mathrm{~min}$ for each. From the scattered X-ray detected on an imaging plate as a two-dimensional image, the excess scattering intensity $\Delta I(\theta)$ at $\theta$ was evaluated as described elsewhere. ${ }^{6,7}$ The square-root plot of $[c / \Delta I(\theta)]^{1 / 2} v s$. $c$ was used to obtain $[c / \Delta I(\theta)]_{c=0}{ }^{1 / 2}$, i.e., the infinite dilution value of $[c / \Delta I(\theta)]^{1 / 2}$.

\section{Dynamic Light Scattering}

The autocorrelation function $g^{(2)}(t)$ was determined as a function of $t$ (correlation time), $\theta$ (between 20 and $60^{\circ}$ ), and $c$ using a light scattering photometer ALV/DLS/SLS-5000 equipped with an ALV-5000E correlator and a YAG laser of the wavelength $532 \mathrm{~nm}$. The first cumulant $\Gamma$ relative to $k^{2}$ (the square of the scattering vector) was evaluated from the slope of a plot of $\ln \left[g^{(2)}(t)-1\right]$ against $k^{2} t$ according to the relation

$$
\ln \left[g^{(2)}(t)-1\right]=\text { const. }-2 \Gamma t+o\left(t^{2}\right)
$$

The translational diffusion coefficient $D$ was determined by double extrapolation of $\Gamma / k^{2}$ to $k=0$ and to $c=0$. The desired hydrodynamic radius $R_{\mathrm{H}}$ was calculated from the relation $R_{\mathrm{H}}=k_{\mathrm{B}} T / 6 \pi \eta_{0} D$, where $k_{\mathrm{B}}$ is the Boltzmann constant and $\eta_{0}$ the solvent viscosity.

\section{Viscometry}

Viscosity measurements were made using Ubbelohde type viscometers. The relative viscosity was evaluated by taking account of the difference between the solution and solvent densities. The Huggins, ${ }^{16}$ Mead-Fuoss, ${ }^{17}$ and Billmeyer ${ }^{18}$ plots were used to determine $[\eta]$.

\section{RESULTS}

Figure 1 shows $A_{2}$ for samples F110-9 and F110-11 in cyclohexane to vanish at a $T$ of $34.5^{\circ} \mathrm{C}$, which coincides with the theta point for cyclohexane solutions of linear polystyrene and PS polymacromonomers F15, F33, and F65. ${ }^{1-3}$

The unfilled and filled circles in Figure 2 represent the $\left\langle S^{2}\right\rangle_{z}$

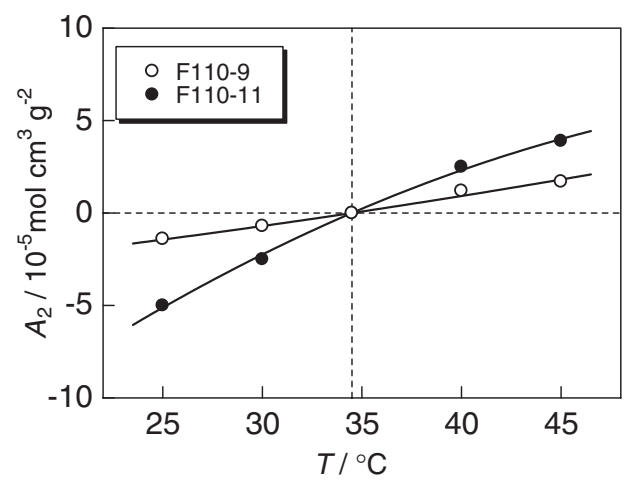

Figure 1. Temperature dependence of second virial coefficient for PS polymacromonomer samples F110-9 and F110-11 in cyclohexane. 


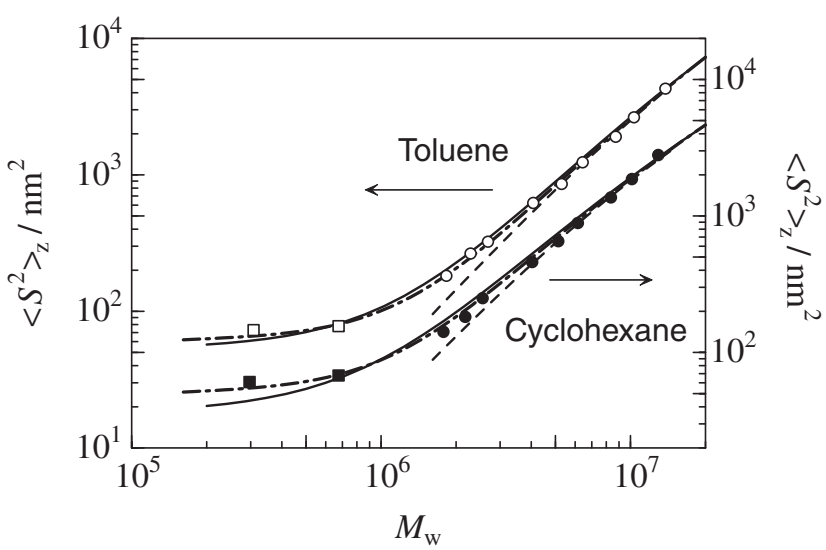

Figure 2. Molecular weight dependence of mean-square radius of gyration for PS polymacromonomer $\mathrm{F} 110$ in toluene at $15.0^{\circ} \mathrm{C}$ (unfilled circles) and cyclohexane at $34.5^{\circ} \mathrm{C}$ (filled circles) determined by light scattering. Unfilled and filled squares represent previous SAXS results ${ }^{19}$ for $\mathrm{F} 110$ in toluene and cyclohexane, respectively. Lines show calculated values from different theories (see the text and Table II).

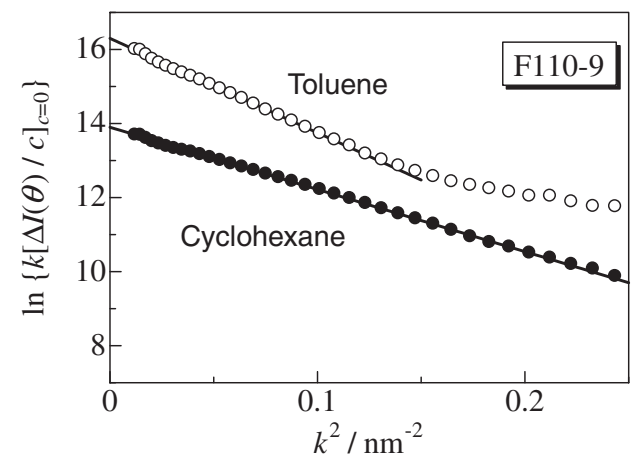

Figure 3. Cross-section plots for sample $\mathrm{F} 110-9$ in toluene at $15.0^{\circ} \mathrm{C}$ (unfilled circles) and cyclohexane at $34.5^{\circ} \mathrm{C}$ (filled circles).

data plotted double-logarithmically against $M_{\mathrm{w}}$ for the F110 polymer in toluene at $15.0^{\circ} \mathrm{C}$ and cyclohexane at $34.5^{\circ} \mathrm{C}$, respectively. The previous SAXS data ${ }^{19}$ for this polymer in toluene and cyclohexane are also shown by the unfilled and filled squares, respectively. The light scattering data in the good and theta solvents are fitted by straight lines with slopes 1.54 and 1.50 (not shown), respectively, while the SAXS data are almost independent of $M_{\mathrm{w}}$.

Figure 3 shows the cross-section plots ${ }^{20}$ of $\ln \left\{k[\Delta I(\theta) / c]_{c=0}\right\}$ vs. $k^{2}$ for F110-9 in cyclohexane (filled circles) and toluene (unfilled circles). The data points for either solvent (in a relatively small $k^{2}$ region in toluene) follow a straight line, whose slope gives $d$ (the cylinder diameter) $16 \mathrm{~nm}$ in cyclohexane and $20 \mathrm{~nm}$ in toluene if equated to $-d^{2} / 16$ (see ref 21 for theoretical discussions on the slope).

The hydrodynamic radii for $\mathrm{F} 110$ samples in toluene (unfilled circles) and cyclohexane (filled circles) are plotted double-logarithmically against $M_{\mathrm{w}}$ in Figure 4 . The plots for toluene and cyclohexane solutions are almost linear with slopes 0.56 and 0.53 , respectively, for $M_{\mathrm{w}}>4 \times 10^{6}$, but the slopes for both solutions are about 0.30 for $M_{\mathrm{w}}<10^{6}$.

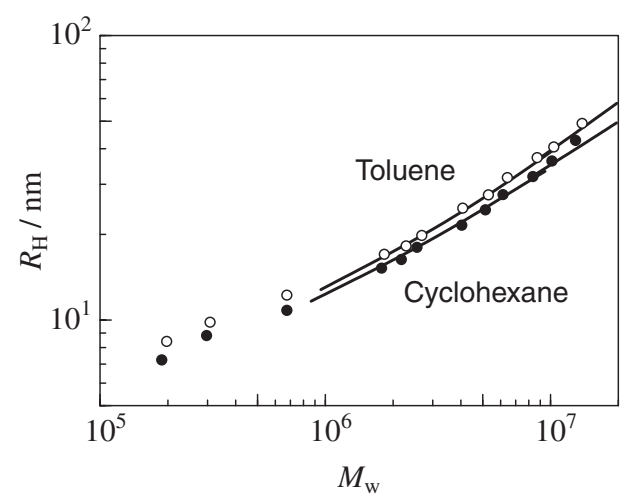

Figure 4. Molecular weight dependence of hydrodynamic radius for $F 110$ in toluene at $15.0^{\circ} \mathrm{C}$ (unfilled circles) and cyclohexane at $34.5^{\circ} \mathrm{C}$ (filled circles). Lines show calculated values for the wormlike chain $^{25,26}$ (see Table II for the parameters used).

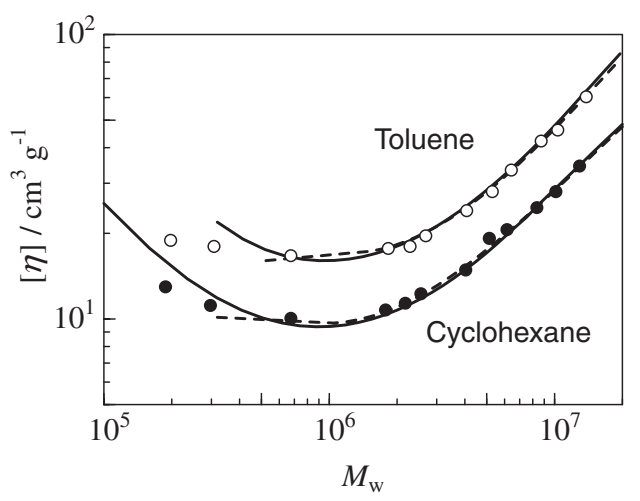

Figure 5. Molecular weight dependence of intrinsic viscosity for F110 in toluene at $15.0^{\circ} \mathrm{C}$ (unfilled circles) and cyclohexane at $34.5^{\circ} \mathrm{C}$ (filled circles). Solid and dashed lines show calculated values for cylindrical ${ }^{27,28}$ and touched-bead ${ }^{29}$ wormlike chains, respectively (see Table II for the parameters used).

The molecular weight dependence of $[\eta]$ for the F110 polymer in the two solvents is shown in Figure 5. While for $M_{\mathrm{w}}>4 \times 10^{6}[\eta]$ increase in proportion to ${M_{\mathrm{w}}}{ }^{v}$ with $v=0.73$ and 0.68 for toluene and cyclohexane solutions, respectively, it has a minimum around $M_{\mathrm{w}}=10^{6}$ in either solvent. We note that no such clear minimum was observed for polymacromonomers with shorter side chains.

The numerical results of $M_{\mathrm{w}},\left\langle S^{2}\right\rangle_{\mathrm{z}}, R_{\mathrm{H}}$, and $[\eta]$ for all the F110 samples are summarized in Table I.

\section{DISCUSSION}

\section{Radius of Gyration}

In our previous studies, ${ }^{1-3}$ it was shown that the main-chain length dependence of $\left\langle S^{2}\right\rangle_{\mathrm{z}}$ for three series of polymacromonomers F15, F33, and F65 in cyclohexane at the theta point is accurately described by the familiar expression for the unperturbed cylindrical KP chain of diameter $d$, i.e., by ${ }^{22}$

$$
\left\langle S^{2}\right\rangle=\left\langle S^{2}\right\rangle_{\mathrm{KP}}+\left(d^{2} / 8\right)
$$

with $^{23}$ 
Table I. Results from static and dynamic light scattering and viscosity measurements on polymacromonomer samples $\mathrm{F} 110$ in cyclohexane (CH) at $34.5^{\circ} \mathrm{C}$ and toluene (Tol) at $15^{\circ} \mathrm{C}$

\begin{tabular}{|c|c|c|c|c|c|}
\hline Sample & Solvent & $M_{\mathrm{w}} / 10^{5}$ & $\begin{array}{c}\left\langle S^{2}\right\rangle_{z} / \\
10^{2} \mathrm{~nm}^{2}\end{array}$ & $R_{\mathrm{H}} / \mathrm{nm}$ & {$[\eta] / \mathrm{cm}^{3} \mathrm{~g}^{-1}$} \\
\hline F110-1 & & 130 & 27.6 & 42.6 & 34.6 \\
\hline F110-2 & & 102 & 18.4 & 36.0 & 28.2 \\
\hline F110-3 & & 84.0 & 13.5 & 31.8 & 24.9 \\
\hline F110-4 & & 61.9 & $8.7_{6}$ & 27.5 & 20.9 \\
\hline F110-5 & & 51.7 & $6.4_{5}$ & 24.3 & 19.5 \\
\hline F110-6 & $\mathrm{CH}$ & 40.6 & $4.5_{4}$ & 21.4 & 15.2 \\
\hline F110-7 & & 25.7 & $2.4_{7}$ & 17.9 & 12.5 \\
\hline F110-8 & & 21.9 & 1.8 & 16.2 & 11.7 \\
\hline F110-9 & & 17.9 & 1.4 & 15.1 & 11.1 \\
\hline F110-10 & & 6.80 & $0.67^{a}$ & 10.8 & 10.4 \\
\hline F110-11 & & 2.99 & $0.60^{a}$ & 8.77 & 11.5 \\
\hline F110-12 & & 1.89 & - & 7.20 & 13.3 \\
\hline F110-1 & & 139 & 42.3 & 48.9 & 60.1 \\
\hline F110-2 & & 104 & 26.1 & 40.4 & 45.9 \\
\hline F110-3 & & 87.8 & 18.8 & 37.0 & 42.0 \\
\hline F110-4 & & 64.7 & 12.2 & 31.5 & 33.5 \\
\hline F110-5 & & 53.3 & $8.4_{7}$ & 27.4 & 28.2 \\
\hline F110-6 & Tol & 41.0 & $6.1_{5}$ & 24.6 & 24.2 \\
\hline F110-7 & & 27.0 & $3.2_{0}$ & 19.7 & 19.6 \\
\hline F110-8 & & 23.0 & $2.6_{2}$ & 18.1 & 18.1 \\
\hline F110-9 & & 18.4 & 1.8 & 16.9 & 17.8 \\
\hline F110-10 & & 6.80 & $0.77^{a}$ & 12.2 & 16.8 \\
\hline F110-11 & & 3.10 & $0.72^{\mathrm{a}}$ & 9.77 & 18.1 \\
\hline F110-12 & & 1.99 & - & 8.37 & 19.0 \\
\hline
\end{tabular}

asAXS results at $25^{\circ} \mathrm{C}$ (ref 19$)$.

$$
\left\langle S^{2}\right\rangle_{\mathrm{KP}}=\frac{L}{6 \lambda}-\frac{1}{4 \lambda^{2}}+\frac{1}{4 \lambda^{3} L}-\frac{1}{8 \lambda^{4} L^{2}}[1-\exp (-2 \lambda L)]
$$

provided the apparent contribution $\delta$ of side chains (near the main-chain ends) to the contour length $L$ (see Figure 3 of ref 8 ) is considered by ${ }^{8}$

$$
L=M / M_{\mathrm{L}}+\delta
$$

Here, $M$ and $M_{\mathrm{L}}$ denote the polymer molecular weight and the molar mass per unit contour length, respectively.

As may be seen from the above equations, $\left\langle S^{2}\right\rangle$ at high $M$ is determined by $\lambda^{-1}$ and $M_{\mathrm{L}}$. The dashed lines in Figure 2 represent the $\left\langle S^{2}\right\rangle_{\mathrm{KP}}$ values computed with $\lambda^{-1}=80$ and $155 \mathrm{~nm}$ for cyclohexane and toluene solutions, respectively, and $M_{\mathrm{L}}=45500 \mathrm{~nm}^{-1}$ for both. Their limited fits for $M_{\mathrm{w}}>$ $4 \times 10^{6}$ suggest significant effects of $d$ and $\delta$. With the $d$ values from the cross-section plots in Figure $3, \delta$ was estimated to be $7 \mathrm{~nm}$ for both cyclohexane and toluene solutions so as to give the closest fit to the data points over the entire $M_{\mathrm{w}}$ range; we note that the two parameters cannot separately be estimated from the present $\left\langle S^{2}\right\rangle_{z}$ data. In Figure 2, except for the lowest $M_{\mathrm{w}}$ sample in cyclohexane, the agreements between the thus computed theoretical solid curves and the data points are satisfactory. In the data analysis for toluene solutions, we considered no intramolecular excluded-volume effect, because the Kuhn statistical segment number $\lambda M_{\mathrm{w}} / M_{\mathrm{L}}$ of about 1.9 for the highest molecular weight sample (F110-1) in toluene is smaller than the value (about 3 ) at which the excluded-volume effect begins to appear.
The main-chain contour length per unit macromonomer is evaluated from the macromonomer molecular weight $\left(1.19 \times 10^{4}\right)$ and $M_{\mathrm{L}}\left(4.55 \times 10^{4} \mathrm{~nm}^{-1}\right)$ to be $0.26 \mathrm{~nm}$, which is close to the values for other PS polymacromonomers $(0.26-$ $0.27 \mathrm{~nm})^{1-3,22}$ and that for the all-trans conformation of the polymethylene chain $(0.25 \mathrm{~nm})$.

We also compare the $\left\langle S^{2}\right\rangle_{\mathrm{z}}$ data with the prediction from a wormlike comb model, which consists of a wormlike main chain of contour length $M_{\mathrm{w}} / M_{\mathrm{L}}\left(M_{\mathrm{L}}=45500 \mathrm{~nm}^{-1}\right)$ and Kuhn length $\lambda^{-1}$ connected by universal joints with wormlike side chains of contour length $l_{\mathrm{s}}$ and Kuhn length $\lambda_{\mathrm{s}}{ }^{-1}$. The expression for $\left\langle S^{2}\right\rangle$ of this model chain is given in the Appendix of ref 6 . We evaluate $l_{\mathrm{s}}$ to be $30.5 \mathrm{~nm}$ from the side chain molecular weight divided by $M_{\mathrm{L}}$ of linear PS $^{24}$ (390 $\mathrm{nm}^{-1}$ ). We note that the thickness (about $1 \mathrm{~nm}$ ) of the individual main and side chains has no significant contribution to $\left\langle S^{2}\right\rangle$. It can be seen in Figure 2 that the dot-dashed lines representing the theoretical $\left\langle S^{2}\right\rangle\left(\lambda^{-1}=80 \mathrm{~nm}\right.$ and $\lambda_{\mathrm{s}}{ }^{-1}=4$ $\mathrm{nm}$ for cyclohexane and $\lambda^{-1}=155 \mathrm{~nm}$ and $\lambda_{\mathrm{s}}{ }^{-1}=5 \mathrm{~nm}$ for toluene) give rather better agreement with the data than the solid lines. These $\lambda_{\mathrm{s}}{ }^{-1}$ values, comparable to the previous estimate $^{6,7}(6 \mathrm{~nm})$ for the F15 polymacromonomer in the two solvents, are appreciably larger than that $(2 \mathrm{~nm})$ for the isolated PS chain, ${ }^{24}$ suggesting that the side chains of the polymacromonomer be somewhat stiffened.

\section{Hydrodynamic Radius}

The Yamakawa-Fujii theory ${ }^{25}$ for the translational friction coefficient allows us to calculate $R_{\mathrm{H}}$ for cylindrical wormlike chains as functions of $\lambda L$ and $\lambda d$. This theory is, however, valid only for $L / d$ larger than about 4 because it does not consider the frictional force from the cylinder ends. This end effect is taken into consideration in the theory of Norisuye et $a l .{ }^{26}$ for wormlike cylinders with hemispheres at both ends, but the theory is applicable only to small $L / d$. In our data analysis, we therefore use the former theory for large $M_{\mathrm{w}}$ and the latter for small $M_{\mathrm{w}}$.

The theoretical values calculated for F110 from these theories are shown by the solid lines in Figure 4, where $M_{\mathrm{L}}$ and $\lambda^{-1}$ are fixed to the values from $\left\langle S^{2}\right\rangle_{\mathrm{z}}\left(\lambda^{-1}=80\right.$ and $155 \mathrm{~nm}$ in cyclohexane and toluene, respectively, and $M_{\mathrm{L}}=45500 \mathrm{~nm}^{-1}$ in both) while $d$ and $\delta$ are chosen so as to give the closest fit to the data points. The two theoretical curves for either solvent are connected at $M_{\mathrm{w}} \sim 9 \times 10^{6}$ and closely fit the data points. The parameters used for the computation are summarized in Table II, along with those estimated from $\left\langle S^{2}\right\rangle_{\mathrm{z}}$. The $d$ values from $R_{\mathrm{H}}$ are appreciably larger than those from $\left\langle S^{2}\right\rangle_{\mathrm{z}}$ (or SAXS) even though the hydrodynamic estimation of $d$ often involves considerable errors. Similar discrepancies have been found in the analyses of $R_{\mathrm{H}}$ data $^{4,5}$ for polymacromonomers with shorter side chains (see ref 5 for detailed discussions).

\section{Intrinsic Viscosity}

Although the wormlike cylinder is a suitable model for polymacromonomer molecules, its theoretical $[\eta]$ elaborated by Yamakawa, Fujii, and Yoshizaki ${ }^{27,28}$ is available only for 
Table II. Molecular parameters explaining different properties for polymacromonomer F110 in cyclohexane $(\mathrm{CH})$ and toluene (Tol)

\begin{tabular}{ccccccc}
\hline Property & Solvent & Model & $M_{\mathrm{L}} / \mathrm{nm}^{-1}$ & $\lambda^{-1} / \mathrm{nm}$ & $d / \mathrm{nm}$ & $\delta / \mathrm{nm}$ \\
\hline$\left\langle S^{2}\right\rangle_{\mathrm{z}}$ & & $\mathrm{C}^{\mathrm{a}}$ & & & 16 & 7 \\
$R_{\mathrm{H}}$ & $\mathrm{CH}$ & $\mathrm{C}$ & \multirow{2}{*}{45500} & 80 & 24 & 5 \\
{$[\eta]$} & $\mathrm{C}$ & & & 15 & 13 \\
{$[\eta]$} & & $\mathrm{TB}^{\mathrm{b}}$ & & 16.5 & 9 \\
\hline$\left\langle S^{2}\right\rangle_{\mathrm{z}}$ & & $\mathrm{C}$ & & & 20 & 6 \\
$R_{\mathrm{H}}$ & $\mathrm{Col}$ & $\mathrm{C}$ & & & 26 & 5 \\
{$[\eta]$} & $\mathrm{C}$ & 45500 & 155 & 21 & 14 \\
{$[\eta]$} & & $\mathrm{TB}$ & & & 21.5 & 11 \\
\hline
\end{tabular}

${ }^{a}$ Cylindrical chain, ${ }^{b}$ Touched-bead chain.

$\lambda d \lesssim 0.2$. For the previously studied polymacromonomers F15, $\mathrm{F} 33$, and $\mathrm{F} 65$, the $\lambda d$ values were all out of this range, and we used the Yoshizaki-Nitta-Yamakawa theory ${ }^{29}$ based on the touched-bead wormlike model for analyses of experimental $[\eta]$ data with the bead diameter equated to $d, 3,8$ because the difference in $[\eta]$ between the two hydrodynamic models diminishes with increasing $\lambda d$ and becomes at most $\pm 5 \%$ at $\lambda d=0.2$.

Table II shows $\lambda d$ for our polymacromonomer F110 to be just about this boundary value $\left(0.13-0.20\right.$ from $\left\langle S^{2}\right\rangle_{\mathrm{z}}$ and $0.17-$ 0.30 from $R_{\mathrm{H}}$ ), so that we may use the both models for the analysis of $[\eta]$. The solid and dashed lines in Figure 5 represent the calculated values from the cylindrical and touched-model theories, respectively, where the $d$ and $\delta$ used are the best-fit values presented in Table II while $\lambda^{-1}$ and $M_{\mathrm{L}}$ are fixed to those from $\left\langle S^{2}\right\rangle_{\mathrm{z}}$. This comparison allows a few points to be made. 1 . The theoretical curves, solid and dashed, satisfactorily fit the data points for both cyclohexane and toluene solutions. 2. In particular, the cylinder model explains the minima of $[\eta]$ around $M_{\mathrm{w}} \sim 10^{6}$. The left end of each line corresponds to the value for the rigid sphere (for the given parameter set); the solid line for cyclohexane ends at a low $M$ of $9.1 \times 10^{4}$ simply because $\delta$ happens to be close to $d$. 3. The $d$ values based on the two models and that from $\left\langle S^{2}\right\rangle_{\mathrm{z}}$ (or SAXS) in each solvent are close to one another, so that, as expected, the cylinder and touched-bead model theories give essentially the same results when $\lambda d \sim 0.2$. It should be noticed that the $d$ values from $[\eta]$ are close to those from $\left\langle S^{2}\right\rangle_{z}$ or SAXS as was found to be the case for the F15 polymer in cyclohexane and toluene.

The observed minimum of $[\eta]$ in either solvent can be expected from the theory for rigid spheroid cylinders, ${ }^{28,30}$ which is written

$$
[\eta] \propto \frac{d^{2} p^{3}}{p-(\delta / d)} F(p)
$$

if the chain-end effect is taken into consideration by eq 3 . Here, $p$ is the axis ratio defined by $L / d$ and $F(p)$ is a known function of $p$. For $\delta / d=0.51-0.87$ (see Table II) eq 4 predicts that $[\eta]$ has a minimum at $p=1.3-2.0$ and hence at $M_{\mathrm{w}}=6 \times 10^{5}-$ $9 \times 10^{5}$ for F110 in agreement with the experimental data in Figure 5. Since the gradual upswing of $[\eta]$ with lowering $M_{\mathrm{w}}$ arises from the factor $(p-\delta / d)^{-1}$ in eq 4 , the significant effect of $\delta$ is apparent at low molecular weights.

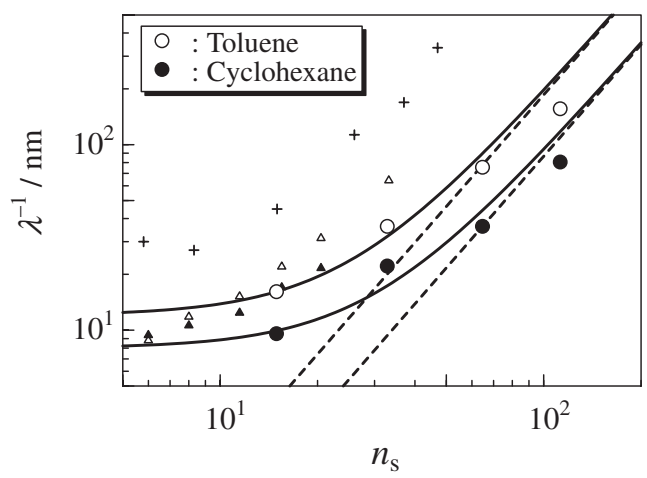

Figure 6. Main-chain stiffness parameter $\lambda^{-1}$ plotted double-logarithmically against polymerization degree $n_{\mathrm{s}}$ of side chain for PS polymacromonomers in toluene at $15.0^{\circ} \mathrm{C}$ (unfilled circles) and cyclohexane at $34.5^{\circ} \mathrm{C}$ (filled circles). Crosses and triangles are literature data for PMMA-PS polymacromonomers. ${ }^{11,14}$ Solid and dashed lines show calculated values of $\lambda^{-1}$ and $\lambda_{\mathrm{b}}{ }^{-1}$, respectively (see the text).

\section{Main Chain Stiffness}

Figure 6 shows that the backbone stiffness for a series of PS polymacromonomers in toluene (the unfilled circles), a good solvent, is systematically higher than that in cyclohexane (the filled circles), a theta solvent, for given $n_{\mathrm{s}}$ (the polymerization degree of side chain) and that both are increasing functions of $n_{\mathrm{s}}$. As indicated by the theoretical solid curves, this $n_{\mathrm{s}}-$ dependence of $\lambda^{-1}$ is almost quantitatively explained by Nakamura and Norisuye's theory, ${ }^{31}$ which reads

$$
\lambda^{-1}=\lambda_{0}^{-1}+\lambda_{\mathrm{b}}{ }^{-1}
$$

where $\lambda_{0}{ }^{-1}$ is the intrinsic backbone stiffness and $\lambda_{\mathrm{b}}{ }^{-1}$ is the contribution arising from side chain-side chain interactions, given by

$$
\begin{aligned}
& \lambda_{\mathrm{b}}{ }^{-1}=\frac{1}{8 \pi}\left(\frac{n_{\mathrm{s}}}{h}\right)^{2} \beta_{2} \quad(\text { good solvent }) \\
& \lambda_{\mathrm{b}}{ }^{-1}=0.02334\left(\frac{n_{\mathrm{s}}}{b}\right)^{2} \frac{\beta_{3}}{h^{3}} \quad \text { (theta solvent) }
\end{aligned}
$$

In the calculation of the solid curves, we have used the following parameters: $h$ (the monomeric contour length of the main chain) $=0.27 \mathrm{~nm}, b$ (the effective bond length of each side chain, i.e., of linear PS) $=0.74 \mathrm{~nm}, \beta_{2}$ (the binary cluster integral) $=0.034 \mathrm{~nm}^{3}$ in toluene, ${ }^{32}$ and $\beta_{3}$ (the ternary cluster integral $)=4 \times 10^{-3} \mathrm{~nm}^{6}$ in cyclohexane, ${ }^{33-35}$ and $\lambda_{0}{ }^{-1}=12$ and $8 \mathrm{~nm}$ in toluene and cyclohexane, ${ }^{31}$ respectively.

The dashed lines representing $\lambda_{\mathrm{b}}{ }^{-1}$ in Figure 6 are fairly close to the data points for the respective solvents at $n_{\mathrm{s}}>50$, but their slope of 2 predicted by eqs 6 and 7 are much higher than those of the experimental relations even in this large $n_{\mathrm{s}}$ region. The exponents predicted by other theories are in a range from 1.62 to $2,^{36-38}$ being similar to that of eqs 6 and 7 . Evidently, experimental data for longer side chains are needed to determine the asymptotic slopes.

Figure 6 includes the early data (the crosses) of Wintermantel et al. ${ }^{11}$ for polymacromonomers consisting of the poly(methyl methacrylate) (PMMA) backbone and PS side chains in toluene (a good solvent) and also the recent results 
from the same group ${ }^{14}$ for the PMMA-PS polymacromonomers in $d_{8}$-toluene and $d_{12}$-cyclohexane at $20^{\circ} \mathrm{C}$ (the unfilled and filled triangles, respectively) determined from the angular dependence of small-angle neutron scattering intensity; note that $d_{12}$-cyclohexane is a poor solvent ${ }^{14}$ but not a theta solvent for the polymacromonomer when judged from the magnitude of positive $A_{2} \cdot{ }^{14}$ Although these recent $\lambda^{-1}$ values are much smaller than the earlier ones, they are still larger than ours. This comparison (with our polymacromonomers) may be rationalized if, as theoretically shown, $\lambda^{-1}$ and hence $\lambda_{\mathrm{b}}{ }^{-1}$ for relatively large $n_{\mathrm{s}}$ are determined predominantly by interactions between or among side chains ${ }^{31}$ (i.e., PS chains). Hence, a remark may be pertinent here.

It is known that the butyl group attached at one end of linear PS leads to non-negligible effects on $A_{2}$ near or at the theta point. ${ }^{39,40}$ This end effect must be non-trivial in polymacromonomers having many side chain ends (unlike our benzyl end side chains). The positive $A_{2}$ of the PMMA-PS polymacromonomers in $d_{12}$-cyclohexane may be caused by such effects of the butyl ends in addition to interactions between PS and PMMA units of different molecules. These interactions between or among unlike groups could lead to larger $\lambda^{-1}$, and may also affect the side chain conformation.

\section{Chain Thickness}

The average values of $d$ estimated from $\left\langle S^{2}\right\rangle_{\mathrm{z}}, R_{\mathrm{H}}$, and $[\eta]$ for our PS polymacromonomers ${ }^{3-8,19}$ in cyclohexane (the filled circles) and toluene (the unfilled circles) are shown as functions of $n_{\mathrm{s}}$ in Figure 7 . Each circle has a large error (maximum error $\pm 29 \%$ for F110 in cyclohexane), but, as is the case with $\lambda^{-1}, d$ is larger in the good solvent than in the theta solvent and is definitely an increasing function of $n_{\mathrm{s}}$ in either solvent. The crosses and triangles representing the data of Schmidt's group $^{11,14}$ for the aforementioned PMMA-PS polymacromonomers show similar trends.

The polymacromonomer chain diameter may be related to the end-to-end distance $\left\langle r^{2}\right\rangle_{\mathrm{KP}}{ }^{1 / 2}$ of each side chain by

$$
d=\left(2\left\langle r^{2}\right\rangle_{\mathrm{KP}}\right)^{1 / 2}
$$

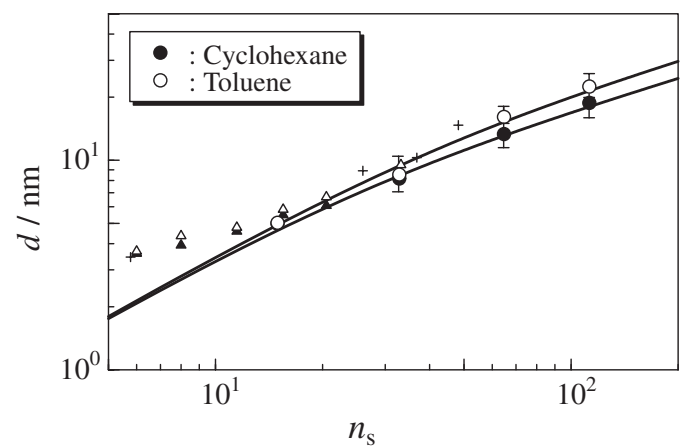

Figure 7. Dependence of $d$ on $n_{\mathrm{s}}$ for PS and PMMA-PS polymacromonomers. The symbols are the same as those used in Figure 6. Lines show the values calculated from eq 8 with eq 9 for wormlike side chains with $\lambda_{\mathrm{s}}{ }^{-1}=6 \mathrm{~nm}$ in cyclohexane and $9 \mathrm{~nm}$ in toluene and $M_{\mathrm{L}}=390 \mathrm{~nm}^{-1}$ (in the two solvents). if the side chains are modeled by the unperturbed KP chain and if their end-to-end vectors are independent of one another (consistent with our wormlike comb model). Here, $\left\langle r^{2}\right\rangle_{\mathrm{KP}}$ is given by

$$
\left\langle r^{2}\right\rangle_{\mathrm{KP}}=\frac{l_{\mathrm{s}}}{\lambda_{\mathrm{s}}}-\frac{1}{2 \lambda_{\mathrm{s}}{ }^{2}}\left[1-\exp \left(-2 \lambda_{\mathrm{s}} l_{\mathrm{s}}\right)\right]
$$

The solid lines fitting the unfilled and filled circles in Figure 7 represent eq 8 with eq 9 for wormlike side chains with $\lambda_{\mathrm{s}}{ }^{-1}=6 \mathrm{~nm}$ in cyclohexane and $9 \mathrm{~nm}$ in toluene and $M_{\mathrm{L}}=390 \mathrm{~nm}^{-1}$ (in both). While the $\lambda_{\mathrm{s}}{ }^{-1}$ of $6 \mathrm{~nm}$ in cyclohexane is essentially consistent with the previous ${ }^{6,7}$ and present analyses of $\left\langle S^{2}\right\rangle_{\mathrm{z}}(6 \mathrm{~nm}$ for F15 and $4 \mathrm{~nm}$ for F110) based on the wormlike comb model, that of $9 \mathrm{~nm}$ in toluene is appreciably larger than the values of $5-6 \mathrm{~nm}$ from $\left\langle S^{2}\right\rangle_{z}$. At present no reasonable explanation can be made for this difference, but these $\lambda_{\mathrm{s}}{ }^{-1}$ values are definitively larger than $2 \mathrm{~nm}$ for the isolated, unperturbed PS chain, ${ }^{24}$ indicating that the side chains of PS polymacromonomers are extended or stretched by interactions between or among them as is the case for the dense polymer brushes on a flat surface. ${ }^{41}$ Labeling experiments to see the dimensions of a side chain is intriguing to get direct information on the side chain conformation.

The data points for toluene and cyclohexane solutions in Figure 7 vary as $n_{\mathrm{s}}{ }^{a}$ with $a=0.75$ and 0.65 , respectively. The former exponent happens to be close to the scaling theory values $0.72-0.75 .^{36,37,42}$

\section{CONCLUSIONS}

We draw the following conclusions from the present work on polymacromonomer F110 consisting of PS with 113 sidechain units in cyclohexane (a theta solvent) and toluene (a good solvent).

1. The molecular weight dependence of $\left\langle S^{2}\right\rangle_{\mathrm{z}}, R_{\mathrm{H}}$, and $[\eta]$ is explained quantitatively by the wormlike chain with $\lambda^{-1}=$ $80 \mathrm{~nm}$ (in cyclohexane) or $155 \mathrm{~nm}$ (in toluene) and $M_{\mathrm{L}}=$ $45500 \mathrm{~nm}^{-1}$ (in both solvents) though $d$ and $\delta$ are allowed to vary depending on the property. The $d$ values determined from the cross-section plot and $[\eta]$ are close to each other, whereas those from $R_{\mathrm{H}}$ are considerably larger than them.

2. The $n_{\mathrm{s}}$-dependence of $\lambda^{-1}$, examined with the aid of previous data ${ }^{1-8}$ for PS polymacromonomers with shorter side-chain lengths, is satisfactorily described by Nakamura and Norisuye's theory ${ }^{31}$ if the intrinsic backbone stiffness is properly chosen. No scaling relation is adequate in the range of $n_{\mathrm{s}}$ below 110 .

3. The chain thickness is larger in the good solvent than in the theta solvent. Its $n_{\mathrm{s}}$-dependence is explained by the relation $d=2^{1 / 2} \times$ (the end-to-end distance of the KP chain) with a linear mass density of $390 \mathrm{~nm}^{-1}$ and a Kuhn segment length $\lambda_{\mathrm{s}}{ }^{-1}$ of $6 \mathrm{~nm}$ in cyclohexane or $9 \mathrm{~nm}$ in toluene. The $\lambda_{\mathrm{s}}{ }^{-1}$ value of $6 \mathrm{~nm}$ in cyclohexane is consistent with the previous and present analyses of $\left\langle S^{2}\right\rangle_{\mathrm{z}}$ for F15 and F110 based on the wormlike comb model, whereas that of $9 \mathrm{~nm}$ in toluene is appreciably larger than the corresponding estimates $(5 \mathrm{~nm}$ 
for $\mathrm{F} 110$ and $6 \mathrm{~nm}$ for $\mathrm{F} 15)$ from $\left\langle S^{2}\right\rangle_{\mathrm{z}}$. This difference between the $\lambda_{\mathrm{s}}{ }^{-1}$ values in the good solvent remains to be seen.

Received: October 4, 2007

Accepted: October 29, 2007

Published: December 11, 2007

\section{REFERENCES}

1. K. Terao, Y. Takeo, M. Tazaki, Y. Nakamura, and T. Norisuye, Polym. J., 31, 193 (1999).

2. K. Terao, Y. Nakamura, and T. Norisuye, Macromolecules, 32, 711 (1999).

3. T. Hokajo, K. Terao, Y. Nakamura, and T. Norisuye, Polym. J., 33, 481 (2001).

4. K. Terao, S. Hayashi, Y. Nakamura, and T. Norisuye, Polym. Bull., 44, 309 (2000)

5. T. Hokajo, Y. Hanaoka, K. Terao, Y. Nakamura, and T. Norisuye, Polym. J., 37, 529 (2005).

6. K. Amitani, K. Terao, Y. Nakamura, and T. Norisuye, Polym. J., 37, 324 (2005).

7. Y. Nakamura, M. Sugiyama, K. Amitani, and T. Norisuye, Polym. J., 39, 1098 (2007).

8. K. Terao, T. Hokajo, Y. Nakamura, and T. Norisuye, Macromolecules, 32, 3690 (1999).

9. O. Kratky and G. Porod, Rec. Trav. Chim., 68, 1106 (1949).

10. M. Wintermantel, M. Schmidt, Y. Tsukahara, K. Kajiwara, and S. Kohjiya, Macromol. Rapid Commun., 15, 279 (1994).

11. M. Wintermantel, M. Gerle, K. Fischer, M. Schmidt, I. Wataoka, H. Urakawa, K. Kajiwara, and Y. Tsukahara, Macromolecules, 29, 978 (1996).

12. K. Fischer and M. Schmidt, Macromol. Rapid Commun., 22, 787 (2001).

13. S. Rathgeber, T. Pakula, A. Wilk, K. Matyjaszewski, and K. L. Beers, J. Chem. Phys., 122, 124904 (2005).

14. B. Zhang, F. Grohn, J. S. Pedersen, K. Fischer, and M. Schmidt, Macromolecules, 39, 8440 (2006).

15. G. C. Berry, J. Chem. Phys., 44, 4550 (1966).
16. M. L. Huggins, J. Am. Chem. Soc., 64, 2716 (1942).

17. D. F. Mead and R. Fuoss, J. Am. Chem. Soc., 64, 277 (1942).

18. F. W. Billmeyer Jr., J. Polym. Sci., 4, 83 (1949).

19. Y. Nakamura, J. Appl. Crystallogr., 40, s577 (2007).

20. O. Glatter and O. Kratky, "Small Angle X-ray Scattering," Academic Press, London, 1982.

21. Y. Nakamura and T. Norisuye, J. Polym. Sci., Part B: Polym. Phys., 42, 1398 (2004).

22. T. Konishi, T. Yoshizaki, T. Saito, Y. Einaga, and H. Yamakawa, Macromolecules, 23, 290 (1990).

23. H. Benoit and P. Doty, J. Phys. Chem., 57, 958 (1953).

24. T. Norisuye and H. Fujita, Polym. J., 14, 143 (1982).

25. H. Yamakawa and M. Fujii, Macromolecules, 6, 407 (1973).

26. T. Norisuye, M. Motowoka, and H. Fujita, Macromolecules, 12, 320 (1979).

27. H. Yamakawa and M. Fujii, Macromolecules, 7, 128 (1974).

28. H. Yamakawa and T. Yoshizaki, Macromolecules, 13, 633 (1980).

29. T. Yoshizaki, I. Nitta, and H. Yamakawa, Macromolecules, 21, 165 (1988).

30. T. Yoshizaki and H. Yamakawa, J. Chem. Phys., 72, 57 (1980).

31. Y. Nakamura and T. Norisuye, Polym. J., 33, 874 (2001).

32. F. Abe, Y. Einaga, T. Yoshizaki, and H. Yamakawa, Macromolecules, 26, 1884 (1993).

33. Y. Nakamura, T. Norisuye, and A. Teramoto, Macromolecules, 24, 4904 (1991).

34. M. Okumoto, K. Terao, Y. Nakamura, T. Norisuye, and A. Teramoto, Macromolecules, 30, 7493 (1997).

35. M. Okumoto, Y. Tasaka, Y. Nakamura, and T. Norisuye, Macromolecules, 32, 7430 (1999).

36. T. M. Birshtein, O. V. Borisov, Y. B. Zhulina, A. R. Khokhlov, and T. A. Yurasova, Vyskomol. Soedin., A29, 1169 (1987).

37. G. H. Fredrickson, Macromolecules, 26, 2825 (1993).

38. A. Subbotin, M. Saariaho, O. Ikkala, and G. ten Brinke, Macromolecules, 33, 3447 (2000).

39. Y. Einaga, F. Abe, and H. Yamakawa, Macromolecules, 26, 6243 (1993).

40. T. Mizuno, K. Terao, Y. Nakamura, and T. Norisuye, Macromolecules, 38, 4432 (2005).

41. S. Yamamoto, M. Ejaz, Y. Tsujii, and T. Fukuda, Macromolecules, 33, 5608 (2000).

42. E. B. Zhulina and T. A. Vilgis, Macromolecules, 28, 1008 (1995). 